Utah State University

DigitalCommons@USU

All Graduate Theses and Dissertations

Graduate Studies

$12-2018$

\title{
Blue and Red Light Effects on Stomatal Oscillations
}

Trevor R. Ballard

Utah State University

Follow this and additional works at: https://digitalcommons.usu.edu/etd

Part of the Biology Commons

\section{Recommended Citation}

Ballard, Trevor R., "Blue and Red Light Effects on Stomatal Oscillations" (2018). All Graduate Theses and Dissertations. 7393.

https://digitalcommons.usu.edu/etd/7393

This Thesis is brought to you for free and open access by the Graduate Studies at DigitalCommons@USU. It has been accepted for inclusion in All Graduate Theses and Dissertations by an authorized administrator of DigitalCommons@USU. For more information, please contact digitalcommons@usu.edu.

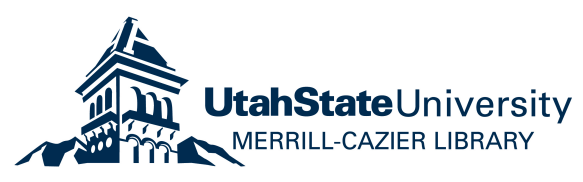




\title{
BLUE AND RED LIGHT EFFECTS ON STOMATAL OSCILLATIONS
}

by

\author{
Trevor R. Ballard
}

A thesis submitted in partial fulfillment

of the requirements for the degree

of

MASTER OF SCIENCE

in

Biology

Approved:

Keith A. Mott, Ph.D.

Major Professor

David Peak, Ph.D.

Committee Member

Tim Gilbertson, Ph.D.

Laurens H. Smith, Ph.D.

Committee Member

Vice President for Research and

Dean of the School of Graduate Studies

UTAH STATE UNIVERSITY

Logan, Utah

2018 
Copyright (C) Trevor R. Ballard 2018

All Rights Reserved 


\begin{abstract}
Blue and Red Light Effects on Stomatal Oscillations
\end{abstract}

by

Trevor R. Ballard, Master of Science

Utah State University, 2018

Major Professor: Keith A. Mott

Department: Biology

The response of stomata to red and blue light was investigated using small fiber optics (66 $\mu \mathrm{m}$ dia) to control light levels on a single pair of guard cells without affecting the surrounding tissue. Low intensity red light $\left(50 \mu \mathrm{mol} \mathrm{m} \mathrm{s}^{-2}\right)$ applied to the entire leaf caused stomata to oscillate continuously for several hours with no apparent decrease in amplitude with time. Adding low intensity blue light $\left(50 \mu \mathrm{mol} \mathrm{m}^{-2} \mathrm{~s}^{-1}\right)$ caused stomata to stop oscillating, but oscillations resumed when the blue light was removed. Adding the same intensity of red light to an oscillating leaf changed the amplitude of the oscillations but did not stop them. When blue light was added to a single guard cell pair (using a fiber optic) in a red-light-illuminated leaf, the stoma formed by that pair stopped oscillating, but adjacent stomata did not. Red light added to a single guard cell pair did not stop oscillations. Finally, blue light applied through a fiber optic to areas of leaf without 
stomata caused proximal stomata to stop oscillating, but distal stomata continued to oscillate. The data suggest that blue light affects stomata via direct effects on guard cells as well as by indirect effects on other cells in the leaf. 


\title{
PUBLIC ABSTRACT
}

\section{Blue and Red Light Effects on Stomatal Oscillations}

\author{
Trevor R. Ballard
}

Plants absorb $\mathrm{CO}_{2}$ through pores in their leaves called stomata, which are known to open and close in response to myriad environmental and physiological triggers. We demonstrate that blue light inhibits stomatal aperture oscillations in both the guard cells and surrounding tissue layers, whereas these oscillations continue under the influence of red light. This observation of blue light behavior agrees with recent research and suggests another physiological pathway for oscillations. 


\section{CONTENTS}

Page

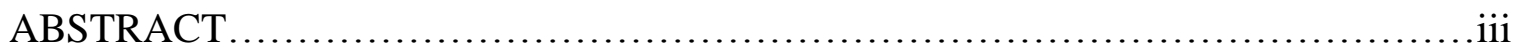

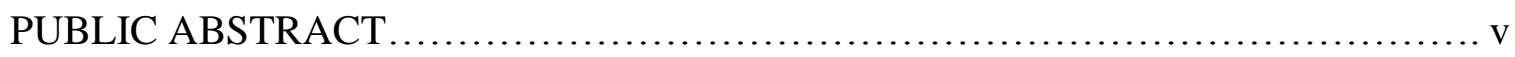

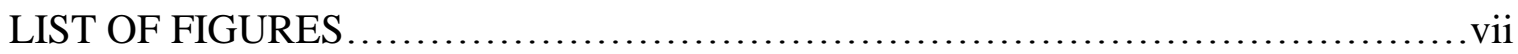

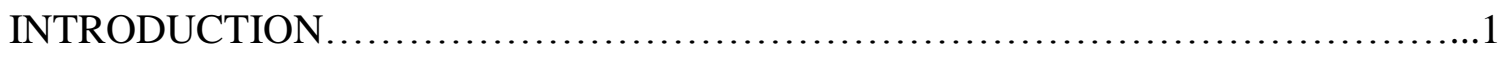

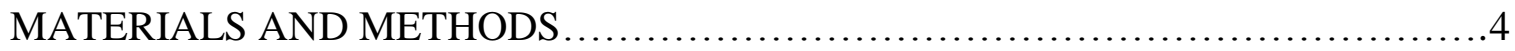

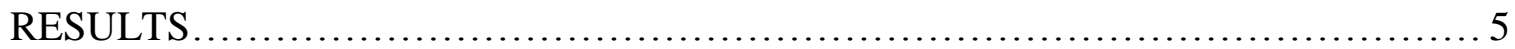

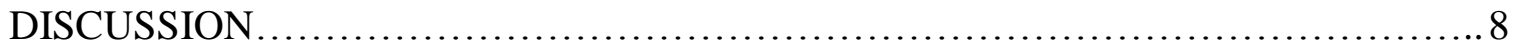

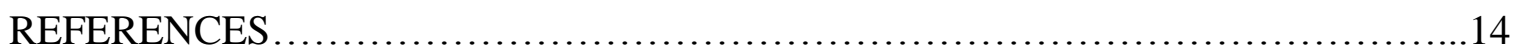




\section{LIST OF FIGURES}

Figure $\quad$ Page

1 Stomata on the abaxial surface of $T$. pallida.........................19

2 Stomatal apertures over time exposed to overhead red light............ 20

3 stomatal apertures over time exposed to overhead red light with additional overhead blue light.......................21

$4 \quad$ stomatal apertures over time exposed to overhead red light with additional overhead red light........................... 22

5 stomatal apertures over time exposed

to overhead red light with additional targeted blue light.

6 stomatal apertures over time exposed to overhead red light with additional targeted red light...................................... 24

$7 \quad$ stomatal apertures over time exposed to overhead red light with additional untargeted blue light................................ 25 


\section{Introduction}

The stomata of a plant's leaves respond to various stimuli such as light, intercellular $\mathrm{CO}_{2}$ concentration, water stress, humidity, oxidative stress, and abscisic acid (Schroeder et al. 2001; Allen et al. 2000). These responses are necessary to provide the plant with the requisite $\mathrm{CO}_{2}$ for photosynthesis, while limiting the loss of water through transpiration. Thus, there is a delicate balancing act that a plant must play out between conserving water and optimizing $\mathrm{CO}_{2}$ uptake, and the stomata, as the portals through which both resources move, are central to this balancing act. Although there is a large body of research on stomatal physiology, and models for the response pathways have been proposed, the signaling mechanisms for these processes are still not fully understood. For example, it is still unknown whether the guard cells of the stomata perceive $\mathrm{CO}_{2}$ and light directly, or whether communication with the rest of the leaf is involved. Although the signaling components for stomatal opening are contained within the guard cells (Inoue 2017), there is substantial evidence to suggest that the mesophyll plays a major part in at least some of the responses (Mott 2009). Leaf epidermes isolated from the mesophyll show a greatly reduced response to both light and $\mathrm{CO}_{2}$ concentration, but isolated epidermes reattached to the mesophyll regain the ability to open and close their stomata (Mott et al. 2008). These epidermal grafts were demonstrated to function across species, suggesting a common signaling mechanism between the mesophyll and the guard cells. Further studies replicated these results (Fujita et al. 2013), as well as suggested an apoplastic pathway for the movement of the proposed mesophyll signal. 
Further, isolated epidermes suspended on a solution containing mesophyll cells or chloroplasts also showed responses to light and $\mathrm{CO}_{2}$ concentrations (Lee, Bowling 1992).

Studies have shown that there are two mechanistically distinct responses of stomata to light, and these have been termed the red and blue light responses (Zeiger, 1983). The red light response has an action spectrum similar to that of chlorophyll, responding to both red and blue light. Because these wavelengths drive photosynthesis, increases in their intensity result in a decrease in intercellular $\mathrm{CO}_{2}$ concentration. It has been suggested that the red light response of stomata is a result of two different factors: a direct signal from the guard cell chloroplasts themselves, and a reduction in intercellular $\mathrm{CO}_{2}$ levels resulting from photosynthesis (Shimazaki et al. 2007). However, whether guard cells sense red light directly is still in dispute (Mott 2009). While several studies have suggested the presence of a red light-sensitive proton pump in guard cells (Schwartz and Zeiger 1984; Serrano, Zeiger and Hagiwara 1988; Olsen et al.2002), other studies have failed to reproduce these findings (Taylor and Assmann 2001; Roelfsema et al. 2001). Arabidopsis mutants lacking chlorophyll in the guard cells of their stomata, while still retaining chlorophyll in mesophyll layers, were found to respond to $\mathrm{CO}_{2}$ and abscisic acid (Azoulay-Shemer et al. 2015). Other studies investigated Arabidopsis mutants lacking chloroplasts in their guard cells (Wang et al. 2014), which retained their opening response, albeit at a lower aperture. These studies suggest that guard cell chloroplasts are not necessary for the responses to light and $\mathrm{CO}_{2}$.

These findings, in conjunction with the results in isolated epidermis leaf grafts discussed above, suggest that the mesophyll is integral to the red light response, 
presumably via a signal from the mesophyll to the guard cells. This signal has demonstrated vapor-phase characteristics and has been suggested to be a vapor phase ion (Mott et al. 2014), but the identity of the signal remains elusive. In contrast, the blue light response has been demonstrated to have a single peak in its action spectrum, around a wavelength of $450 \mathrm{~nm}$. This response appears to be independent of photosynthesis (Zeiger et al. 2002), although recent studies have suggested that chloroplasts within the guard cells are mandatory for the blue light response to occur in Arabidopsis (Suetsugu et al. 2014). Arabidopsis mutants lacking functional photl and phot2 genes lost the ability to respond directly to blue light, but had this ability restored when a transformant restored the phot 1 protein, suggesting another biochemical requirement for the blue light response in phototropins (Doi et al. 2004). Additionally, quantum efficiency of the blue light response has been demonstrated to be higher than that of red light (Zeiger and Zhu, 1998), and blue light has been demonstrated to inhibit stomatal oscillations (Zait et al. 2017)

There is consensus in the literature that guard cells respond directly to blue light (Mott 2009), but there is also evidence to suggest that the phototropin response specific to blue light is present in the mesophyll (Stoelzle et al. 2002; Shimazaki et al. 2007). This suggests that the blue light response of stomata may be present in both the mesophyll and the guard cells.

The goal of this study was to investigate the response of the guard cells and the mesophyll to red and blue light. By using a tiny fiber optic inserted into the substomatal 
cavity, we were able to illuminate guard cells with red or blue light without illuminating the mesophyll and record stomatal responses via direct observation of stomatal apertures.

\section{Materials and Methods}

Tradescantia pallida (Rose) D. Hunt plants were grown in an environmentally controlled greenhouse with day and night temperatures of $30^{\circ} \mathrm{C}$ and $20^{\circ} \mathrm{C}$, respectively. Day time was kept at 16 hours of light through use of high-pressure sodium lamps with a PFD of approximately $1000 \mu \mathrm{mol} \mathrm{m} \mathrm{m}^{-2}$ at the top of the plants, with night time kept at 8 hours of darkness. The plants were grown in 1 gallon pots filled with a 1:1:1 mix of peat moss, vermiculite, and perlite. They were watered twice a day with $9.1 \mathrm{~mm} \mathrm{~N}, 1.8 \mathrm{~mm} \mathrm{P}$, and 2.7 mm K dilute fertilizer injected into the water supply (Peter's 20-10-20; Grace Sierra Horticultural Products Co., Milpitas, CA, USA). Leaves selected were fully mature, healthy, and undamaged, with a preference for tactile turgidity to help mitigate damage caused by the insertion of a fiber optic.

Leaves were observed using a microscope with the abaxial surface of the leaf facing the objective (T. pallida is hypostomatous). A viewing area was selected that contained at least seven stomata close enough together in the focal plane to be accurately measured. For experiments requiring insertion of a fiber optic through the mesophyll, a $66 \mu \mathrm{m}$ (O.D.) optic fiber (Polymicro Technologies, Phoenix, AZ, USA) was inserted through the adaxial surface and the mesophyll using a micromanipulator. The fiber optic was positioned visually with the fiber light source on to ensure that only one stoma was 
illuminated by the fiber, as shown in Figure 1. Leaves in which the fiber caused visual mesophyll damage were not used, nor were leaves in which the fiber-illuminated stomata did not open when the abaxial surface was illuminated. Light to the fiber optic and to the abaxial surface of the leaf was supplied by LEDs (Rebel Star; Luxeon Star LEDs, Randolph, Vermont, USA). A 627 nm LED was used for the red light, and a $470 \mathrm{~nm}$ LED was used for the blue light. Gas concentrations were kept constant at $150 \mathrm{ppm} \mathrm{CO}_{2}$ by mixing $\mathrm{CO}_{2}$-free air and $1 \% \mathrm{CO}_{2}$ using a mass flow controller. This gas mixture flowed through a water bubbler at room temperature to maintain the vapor pressure difference between leaf and air to be approximately $1 \mathrm{kPa}$. Digital images of the leaf surface were captured using a megapixel microscope camera (3.3 MPX; Imaging Planet, Goleta, CA, USA), and stomatal apertures were measured using the program ImageJ.

\section{Results}

When the abaxial surface of an intact leaf of T. pallida was illuminated with 50 $\mu \mathrm{mol} \mathrm{m} \mathrm{m}^{-2} \mathrm{~s}^{-1}$ of red light, stomata opened and showed oscillations. The amplitude of the oscillations did not decrease noticeably with time, even over several hours (i.e., they were not damped). Five oscillations with a period of approximately 1 hour were recorded before terminating the experiment. This experiment was repeated three times with similar results. Minor variations in oscillation period and amplitude were noted between experiments and individual stomata. A representative time course for this experiment is shown in Figure 2. 
To investigate the effect of blue light on oscillations, the abaxial surface of an intact leaf from T. pallida was exposed to red light at a photon intensity of $50 \mu \mathrm{mol} \mathrm{m} \mathrm{m}^{-2}$ ${ }^{1}$ as above. However, in this experiment $50 \mu \mathrm{mol} \mathrm{m} \mathrm{m}^{-2} \mathrm{~s}^{-1}$ of blue light was added to the abaxial surface of the leaf after the first full oscillation. No stomatal oscillations were observed while the leaf was illuminated with both red and blue light, but upon removal of the blue light (while maintaining $50 \mu \mathrm{mol} \mathrm{m} \mathrm{m}^{-1}$ of red light), stomata resumed oscillations. The experiment was performed in triplicate, with only minor variations in oscillation period and amplitude noted between experiments. Figure 3 shows a representative time course for this experiment.

To verify that the inhibition of oscillations observed in Figure 3 was caused by the presence of blue light, and not simply by the increase in overall photon intensity, a third experiment was performed in which $50 \mu \mathrm{mol} \mathrm{m} \mathrm{m}^{-2}$ of red light was added instead of blue light. In similar fashion to the previous experiments, red light at an intensity of $50 \mu \mathrm{mol}$ $\mathrm{m}^{-2} \mathrm{~s}^{-1}$ was initially applied to the abaxial surface of an intact T. pallida leaf. After the first oscillation, an additional $50 \mu \mathrm{mol} \mathrm{m} \mathrm{m}^{-2}$ of red light was added (instead of blue light). Unlike the blue light experiment shown in Figure 3, oscillations continued throughout the period of increased red-light exposure. Figure 4 shows a representative time course for this experiment, demonstrating that oscillations continue even with an increase in red light intensity. However, the minimum apertures of the oscillations were higher in these experiments than in experiments with only $50 \mu \mathrm{mol} \mathrm{m} \mathrm{s}^{-2}$ of red light.

To further investigate the ability of blue light to inhibit stomatal oscillations, as well as to determine whether this blue light response is located within the guard cells 
themselves, a small (66 $\mu \mathrm{m}$ diameter) fiber optic was pushed through the adaxial surface of an intact leaf and into the substomatal cavity of a stoma on the abaxial surface. The end of the fiber optic was positioned such that it illuminated a targeted pair of guard cells but did not directly illuminate the mesophyll. The leaf was then exposed to red light at an intensity of $50 \mu \mathrm{mol} \mathrm{m} \mathrm{m}^{-2} \mathrm{~s}^{-1}$ on the abaxial surface. In some experiments the stoma with the fiber optic below it did not open in response to the red light, presumably because of damage to the surrounding mesophyll. However, for experiments in which the target stoma opened in response to the red light, blue light was then provided through the fiber optic at an intensity of $50 \mu \mathrm{mol} \mathrm{m} \mathrm{m}^{-2}$. After several hours of exposure to both the red light supplied over the entire leaf and the blue light supplied through the fiber optic, the blue light was removed, returning the leaf to only red light. Two stomata were measured in these experiments: one that was illuminated by the blue light from the fiber optic, and one over a millimeter away from the inserted fiber optic. Three experiments were performed with similar results, and typical results are shown in Figure 5. Both stomata opened under red light and showed an initial oscillation. The stoma that received only red light continued to oscillate throughout the entire experiment. However, the stoma exposed to the blue light from the fiber optic opened substantially and did not oscillate during the four hours that it was exposed to the blue light. It closed rapidly when the blue light was removed.

To demonstrate that inhibition of oscillations by the addition of blue light through the fiber optic was specific to blue light, and not simply caused by the higher photon intensity or physical changes caused by the fiber optic itself, the same experimental setup 
as above was used, but in this case the fiber optic was used to deliver red light at $50 \mu \mathrm{mol}$ $\mathrm{m}^{-2} \mathrm{~s}^{-1}$. Again, red light at $50 \mu \mathrm{mol} \mathrm{m} \mathrm{m}^{-2} \mathrm{~s}^{-1}$ was first applied to the entire leaf, and the light from the fiber optic was turned on after the first oscillation. Two stomata were observed: one that was illuminated by the fiber optic and one over a millimeter away from the fiber, and in this case, both stomata oscillated throughout the entire experiment. The experiment was successfully repeated three times, and typical data are shown in Figure 6.

To further investigate whether the blue light was sensed by the guard cells or by other tissues in the leaf, a fiber optic was placed close to the abaxial surface without penetrating the epidermis. This allowed a blue light to be applied over a $200 \mu \mathrm{m}$ diameter area of the leaf, as far away as possible from any guard cells. To start the experiment, red light at $50 \mu \mathrm{mol} \mathrm{m} \mathrm{s}^{-1}$ was applied to the entire leaf. After the first oscillation, blue light from the fiber was turned on. Two stomata were observed, one $650 \mu \mathrm{m}$ away from the area of blue light and another $1.5 \mathrm{~mm}$ from the area of the blue light. Although the stoma farthest from the blue light continued to oscillate throughout the experiments, the stoma closest to the blue light opened substantially and did not oscillate. Figure 7 shows typical results for this experiment. The experiment was performed three times with similar results.

\section{Discussion}

The data presented in this manuscript show differences between red and blue light effects on stomatal behavior in intact leaves. One immediately obvious distinction is the 
inhibition of stomatal oscillations by blue light, which was also recently documented in banana leaves (Zait et al. 2017). In our study, stomatal oscillations were observed to occur when leaves were illuminated with red light but were absent under blue light. The effect was pronounced enough that even when stomata were oscillating under red light, the addition of blue light was sufficient to stop oscillations, and removing the blue light allowed the oscillations to resume, as shown in Figures 3 and 7. The effect of the added blue light on oscillations was not simply due to the increase in overall photon intensity because adding the same amount of red light did not stop the oscillations (Figure 4). This suggests that that the inhibitory effect observed with blue light was caused specifically by the blue light, rather than by a simple increase in photon intensity. However, adding additional red light frequently caused the stomata to oscillate out of sync with each other (note the large error bars in Figure 3), and typically caused the minimum apertures of the oscillations to increase. Comparing Figure 2 and Figure 4 of our study demonstrates this damping of the oscillatory effect, though the oscillations remain. This indicates that while the stomata were affected by the higher levels of red light, the inhibition of oscillations remains a distinctly blue light-specific behavior.

By using a fiber optic inserted through the adaxial surface, we were able to illuminate guard cells (on the abaxial surface) without illuminating the mesophyll (Figure 5). These experiments show that the inhibition of stomatal oscillations by blue light was a direct effect of blue light on the guard cells. Furthermore, guard cells not illuminated by the blue light from the fiber optic continued to oscillate, suggesting that the effect was not propagated laterally in the leaf. 
Replicating this experiment with a red light source through the fiber optic failed to inhibit stomatal oscillations; the guard cells illuminated by the red light supplied by the fiber optic behaved almost identically to guard cells not illuminated by the light from the fiber. This result suggests that the guard cells do not respond to red light directly, and supports the idea that much of the red light response of stomata depends on a signal from the mesophyll (Mott et al. 2008). In contrast, the response of the guard cells to blue light applied with the fiber agrees with previous observations that the guard cells can respond directly to blue light, even when separated from the mesophyll (Lee, Bowling 1993). Surprisingly, blue light also inhibited oscillations when applied to areas of the leaf that lacked guard cells. This suggests that there are multiple sites for the perception of the blue light response, although our data do not allow us to determine if the response originates in the mesophyll, epidermis, or both.

Stomata have been shown to exhibit oscillations in a wide variety of plants including Citrus sinensis, Helianthus annuus, and Gossypium barbadense (e.g., Steppe et al. 2006; Cox 1968; Ehrler et al. 1965). While there is significant variation in stomatal oscillation periods across species, the oscillations tend to be on the order of tens of minutes and may be damped or undamped. Oscillations have also been demonstrated to occur in patches on the leaf surface of Xanthium strumarium (West et al. 2005), and these patches have been shown to move in waves across the leaf surface. Despite the "patchy" behavior of oscillations, individual stomata have been shown to synchronize their oscillations with neighboring stomata, and leaves across an entire plant have been demonstrated to oscillate in sync with each other (Marenco et. al 2006, Rand et. al 1982). 
While the mechanisms for the regulation of these oscillations are not yet fully understood, there is consensus that physiological feedback control is involved (Yang et al. 2005). Oscillations in levels of various chemical messengers within guard cells such as calcium and hydrogen have been demonstrated in response to light in Vicia faba leaves (Shabala and Newman 1999), but the periods of chemical oscillations have been demonstrated to be much shorter than the stomatal oscillations, making the link between chemical and stomatal oscillations unclear. Oscillations have been proposed to result from hydraulic interactions between the guard cells and the subsidiary cells as the rates of water supply from the xylem ebb and flow in response to the rate of water loss from the stomata (Farquhar 1974).

However, our data and those of Zait et. al (2017) show that oscillations also depend on light properties, and that addition of blue light can suppress oscillatory behavior. In the study of Zait et al. (2017) blue light was added to the entire leaf, and they showed that blue light increased leaf water supply, thereby reducing turgor pressure loss. They suggest that blue light increases the hydraulic conductivity for water transport from xylem to epidermis, which then reduces the effect of transpiration on epidermal turgor and thereby prevents oscillations. Our data are consistent with this suggestion because blue light added to areas of the leaf without stomata inhibited oscillations (Figure 7), suggesting that at least part of the effect of blue light was not a direct response of the guard cells to blue light. However, in our study oscillations were also inhibited when a pair of guard cells were illuminated with blue light using a fiber optic (Figure 5). The level of blue light applied to the guard cells was very low $\left(50 \mathrm{mmol} \mathrm{m}^{-2} \mathrm{~s}^{-1}\right)$ and very little 
of that light spread to surrounding cells (Figure 1). Therefore, this result suggests that inhibitory effects of blue light on oscillations can also be caused by direct absorption of blue light by guard cells. Taken together, therefore, our data and those of Zait et al. (2017) suggest that there are at least two effects of blue light on stomatal oscillations.

It should be noted that there are several differences between the oscillations observed in this study and those observed by Zait et al. (2017). First, oscillations in this study were present under conditions of low VPD (approximately $1 \mathrm{kPa}$ ), whereas those observed by Zait were present only at high VPD (2.5 kPa). Second, the oscillations observed by Zait showed a period of approximately $25 \mathrm{~min}$, while the oscillations in this study had a period of almost 2 hours. And finally, the oscillations observed by Zait showed pronounced damping over time, while those observed in this study showed no signs of damping even after several cycles. These differences may suggest differences in the species-dependent physiological feedback responsible for the oscillation. It is therefore remarkable that blue light was effective in eliminating oscillations in both studies.

In summary, our data are consistent with the findings of Zait et al. (2017) that blue light inhibits stomatal oscillations. Furthermore, they support the idea that at least part of the effect arises from blue light absorption by cells other than guard cells. However, our data also show that oscillations can be inhibited by direct absorption of blue light by guard cells, which suggests that there may be more than one effect of blue light on stomatal behavior. 


\section{Conflicts of Interest}

The authors declare no conflicts of interest. 


\section{References}

Azoulay-Shemer T., Palomares A., Bagheri A., Israelsson-Nordstrom M., Eingineer C., Bargmann B., Stephan A., Schroeder J. (2015) Guard cell photosynthesis is critical for stomatal turgor production, yet does not directly mediate $\mathrm{CO} 2$ - and ABA-induced stomatal closing. The Plant Journal 83, 567-581.

Cox EF. (1968). Cyclic changes in transpiration of sunflower leaves in a steady environment. Journal of Experimental Botany 19, 167-175.

Doi M., Shigenaga A., Emi T., Kinoshita T., Shimazaki K. (2004) A transgene encoding a blue- light receptor, phot1, restores blue- light responses in the Arabidopsis phot 1 phot 2 double mutant. Journal of Experimental Botany 55, 517-523.

Ehrler WL, Nakayama FS, van Bavel CHM (1965). Cyclic changes in water balance and transpiration of cotton leaves in a steady environment. Physiologia Plantarum 18, 766-775.

Farquhar G., Cowan I. (1974). Oscillations in Stomatal Conductance. Plant Physiology 54, 769-772.

Fujita T., Noguchi K., Terashima I. (2013) Apoplastic mesophyll signals induce rapid stomatal responses to CO2 in Commelina communis. New Phytologist 199, 395406.

Inoue S., Kinoshita T. (2017) Blue Light Regulation of Stomatal Opening and the Plasma Membrane H+-ATPase. Plant Physiology 174, 531-538. 
Lee J.S., Bowling D.J.F (1993) The effect of a mesophyll factor on the swelling of guard cell protoplasts of Commelina communis. Journal of Plant Physiology 142, 203207.

Lee J.S., Bowling D.J.F. (1992) Effect of the mesophyll on stomatal opening in Commelina communis. Journal of Experimental Botany 43, 951-957.

Marenco R.A., Siebke K., Farquhar G.D., Ball M.C. (2006) Hydraulically based stomatal oscillations and stomatal patchiness in Gossypium hirsutum. Functional Plant Biology 33(12), 1103-1113.

Mott K., Berg D., Hunt S., Peak D. (2014) Is the signal from the mesophyll to the guard cells a vapour-phase ion? Plant, Cell \& Environment 37, 1184-1191.

Mott K.A. (2009) Opinion: Stomatal responses to light and CO2 depend on the mesophyll. Plant, Cell and Environment 32, 1479-1486.

Mott K.A., Sibbernsen E.D., Shope J.C. (2008) The role of the mesophyll in stomatal responses to light and CO2. Plant, Cell \& Environment 31, 1299-1306.

Olsen R.L., Pratt R.B., Gump P., Kemper A. \& Tallman G. (2002) Red light activates a chloroplast-dependent ion uptake mechanism for stomatal opening under reduced CO2 concentrations in Vicia spp. New Phytologist 153, 497-508.

Rand R.H., Storti D.W., Upadhyaya S.K., Cooke J.R. (1982) Dynamics of coupled stomatal oscillators. Journal of Mathematical Biology 15, Issue 2, 121-149. 
Roelfsema M.R.G., Steinmeyer R., Staal M. \& Hedrich R. (2001) Single guard cell recordings in intact plants: light induced hyperpolarization of the plasma membrane. The Plant Journal 26, 1-13.

Schroeder JI, Kwak JM, Allen GJ (2001). Guard cell abscisic acid signaling and engineering drought hardiness in plants. Nature 410, 327-330.

Schwartz A., Zeiger E. (1984) Metabolic energy for stomatal opening. Roles of photophosphorylation and oxidative phosphorylation. Planta 161, 129-136.

Serrano E.E., Zeiger E., Hagiwara S. (1988) Red light stimulates an electrogenic proton pump in Vicia guard cell protoplasts. Proceedings of the National Academy of Sciences of the United States of America 85, 436-440.

Shabala S., Newman I. (1999). Light-Induced Changes in Hydrogen, Calcium, Potassium, and Chloride Ion Fluxes and Concentrations from the Mesophyll and Epidermal Tissues of Bean Leaves. Understanding the Ionic Basis of LightInduced Bioelectrogenesis. Plant Physiology 119, 1115-1124.

Shimazaki K., Doi M., Assmann S.M., Kinoshita T. (2007) Light regulation of stomatal movement. Annual Review of Plant Biology 58, 219-247.

Steppe K., Dzikiti S., Lemeur R., Milford J. (2006). Stomatal Oscillations in Orange Trees under Natural Climatic Conditions. Annals of Botany 97, 831-835.

Stoelzle S., Kagawa T., Wada M., Hedrich R., Dietrich P. (2002). Blue light activates calcium-permeable channels in Arabidopsis mesophyll cells via the phototropin 
signaling pathway. Proceedings of the National Academy of Sciences 100, 14561461.

Suetsugu N., Takami T., Ebisu Y., Watanabe H., Iiboshi C., Doi M., Shimazaki K. (2014) Guard Cell Chloroplasts Are Essential for Blue Light-Dependent Stomatal Opening in Arabidopsis. PLoS ONE 9.

Taylor A.R. \& Assmann S.M. (2001) Apparent absence of a redox requirement for blue light activation of pump current in broad bean guard cells. Plant Physiology 125, $329-338$.

West J., Peak D., Peterson J., Mott K. (2005) Dynamics of stomatal patches for a single surface of Xanthium strumarium L. leaves observed with fluorescence and thermal images. Plant, Cell and Environment 28, 633-641.

Yang H., Zhang J., Zhang X. (2005). Regulation Mechanisms of Stomatal Oscillation. Journal of Integrative Plant Biology 47(10), 1159-1172.

Zait, Y., Shapira, O., Schwartz, A. (2017) The effect of blue light on stomatal oscillations and leaf turgor pressure in banana leaves. Plant, Cell \& Environment 40, 11431152.

Zeiger E, Talbott LD, Frechilla S, Srivastava A, Zhu JX. 2002. The guard cell chloroplast: a perspective for the twenty-first century. New Phytologist 153, 415424. 
Zeiger E, Zhu J (1998) Role of zeaxanthin in blue light photoreception and the modulation of light-CO2 interactions in guard cells. Journal of Experimental Botany 49, 433-442.

Zeiger E. 1983. The biology of stomatal guard cells. Annual Review of Plant Physiology 34, 441-75. 


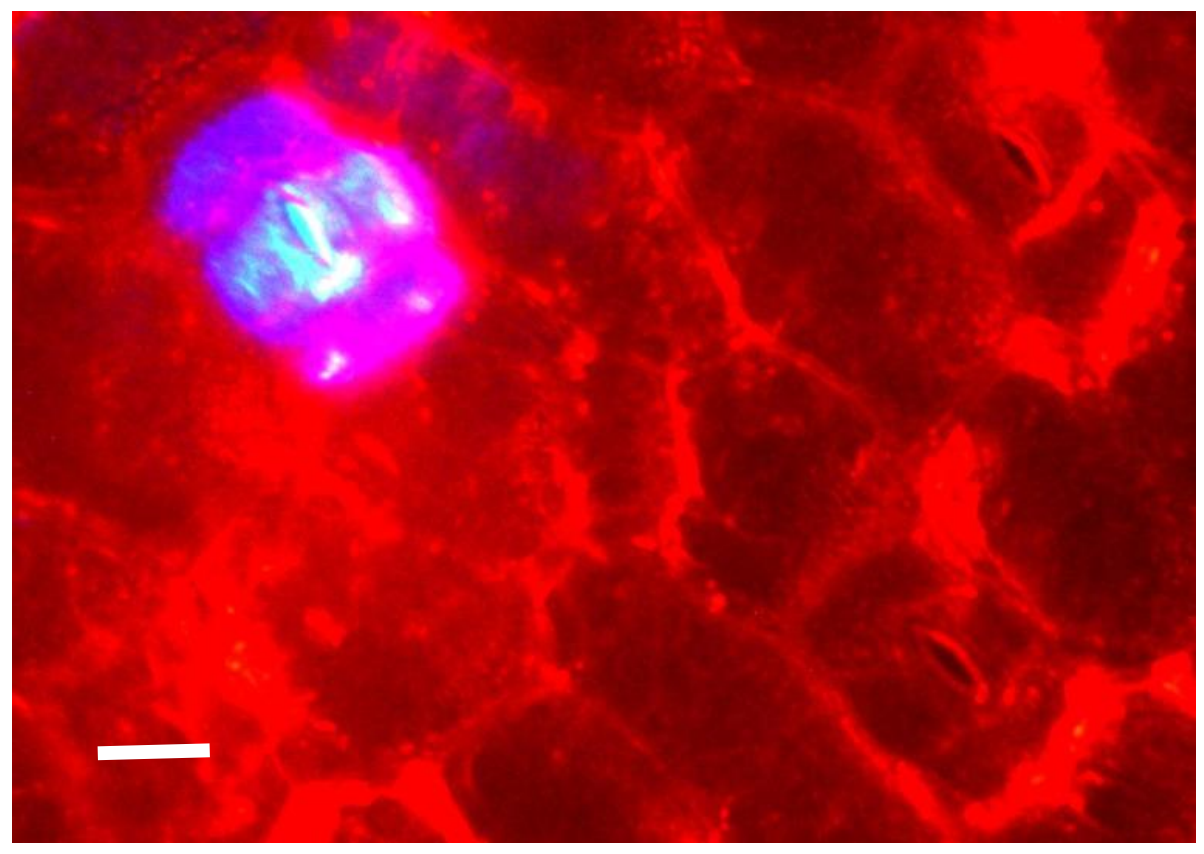

Figure 1. Stomata on the abaxial surface of T. pallida. Background red light is incident on the abaxial surface of the leaf. One stoma is illuminated by blue light via a fiber optic inserted into the substomatal cavity from the adaxial surface (see Materials and Methods). The scale bar shows $100 \mu \mathrm{m}$. 


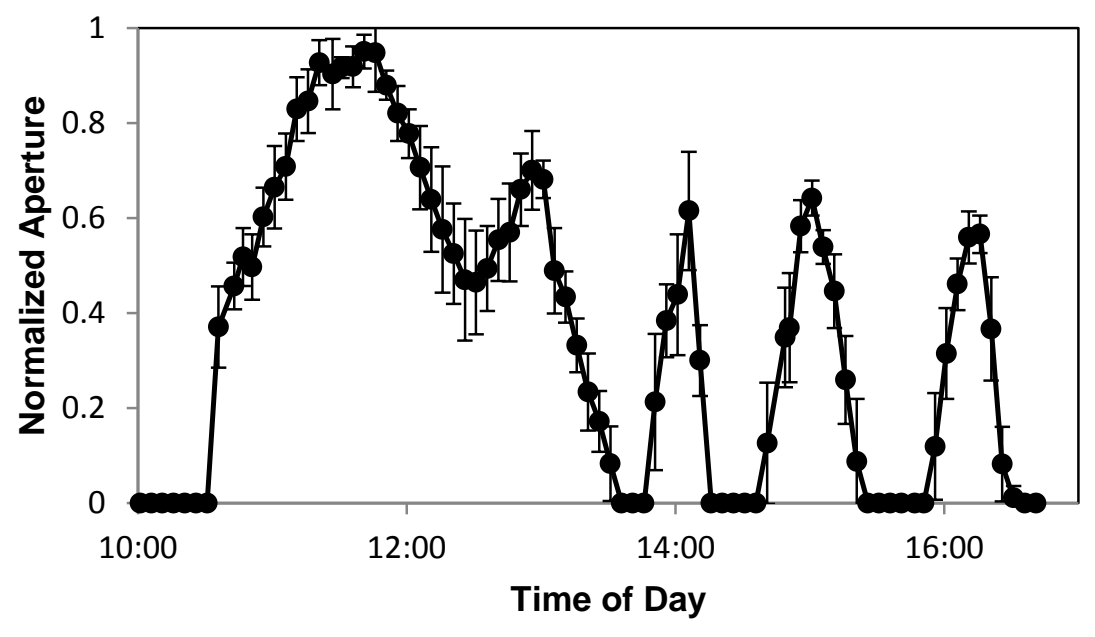

Figure 2. Normalized stomatal apertures over time from a T. pallida leaf subjected to 50 $\mu \mathrm{mol} \mathrm{m} \mathrm{m}^{-2}$ of red light over the entire abaxial surface. Stomatal apertures were measured in five minute intervals for over six hours with no changes in photon intensity.

Five individual stomata were measured, normalized against their individual maximum apertures, and then averaged. Bars show one standard deviation on either side of the mean. 


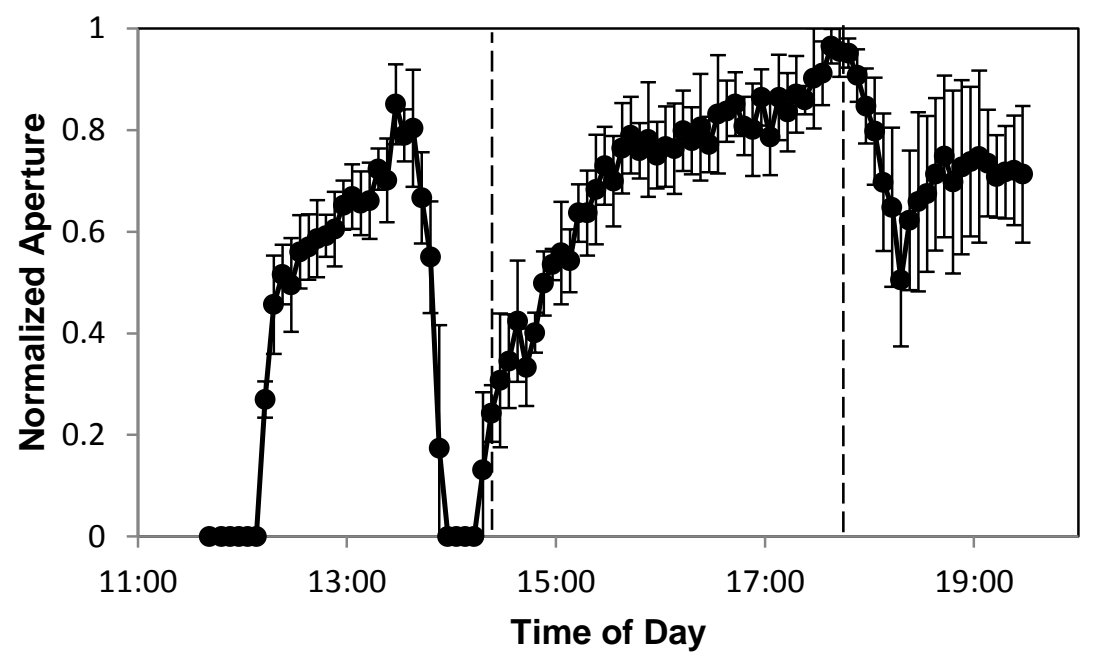

Figure 3. Normalized stomatal apertures over time from a T. pallida leaf subjected to 50 $\mu \mathrm{mol} \mathrm{m} \mathrm{s}^{-1}$ of red light over the entire abaxial surface. An additional $50 \mu \mathrm{mol} \mathrm{m}^{-2} \mathrm{~s}^{-1}$ of blue light was added to the red light at 14:51, and was subsequently removed at 17:55, with measurements taken every five minutes. Five individual stomata were measured, normalized against their individual maximum apertures, and then averaged. Bars show one standard deviation on either side of the mean. 


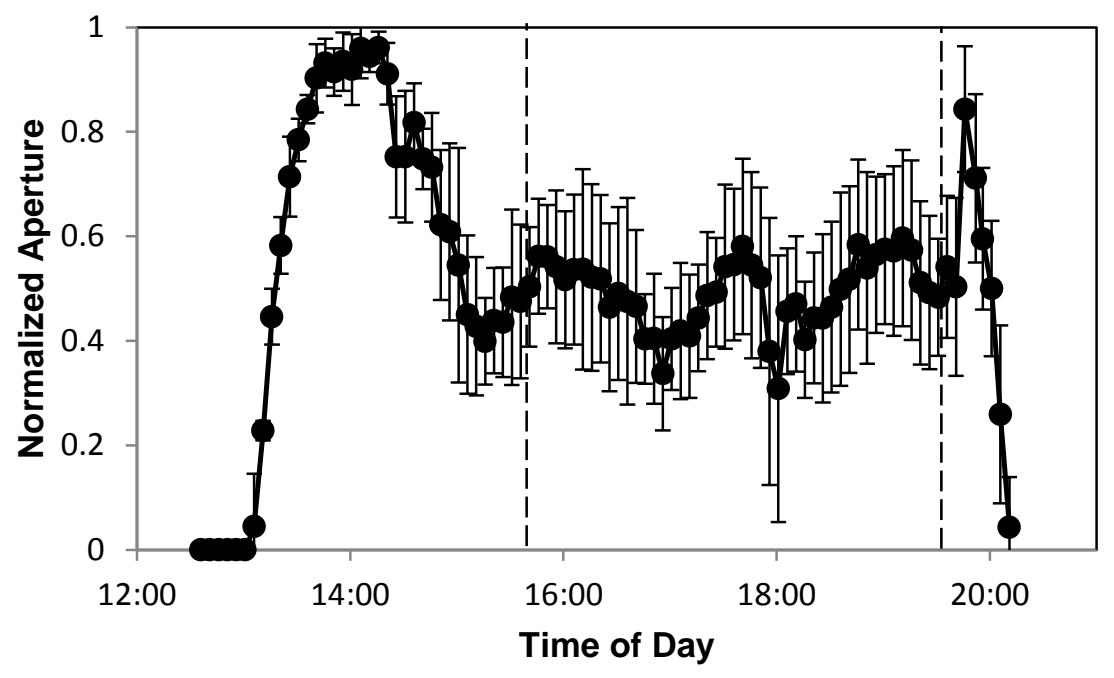

Figure 4. Normalized stomatal apertures over time from a T. pallida leaf subjected to 50 $\mu \mathrm{mol} \mathrm{m} \mathrm{m}^{-1}$ of red light over the entire abaxial surface. The photon intensity of red light was increased to $100 \mu \mathrm{mol} \mathrm{m} \mathrm{m}^{-2}$ at 15:51, and was then reduced back to $50 \mu \mathrm{mol} \mathrm{m} \mathrm{m}^{-2} \mathrm{~s}^{-1}$ at 19:22, with measurements taken every five minutes. Five individual stomata were measured, normalized against their individual maximum apertures, and then averaged. Bars show one standard deviation on either side of the mean. 


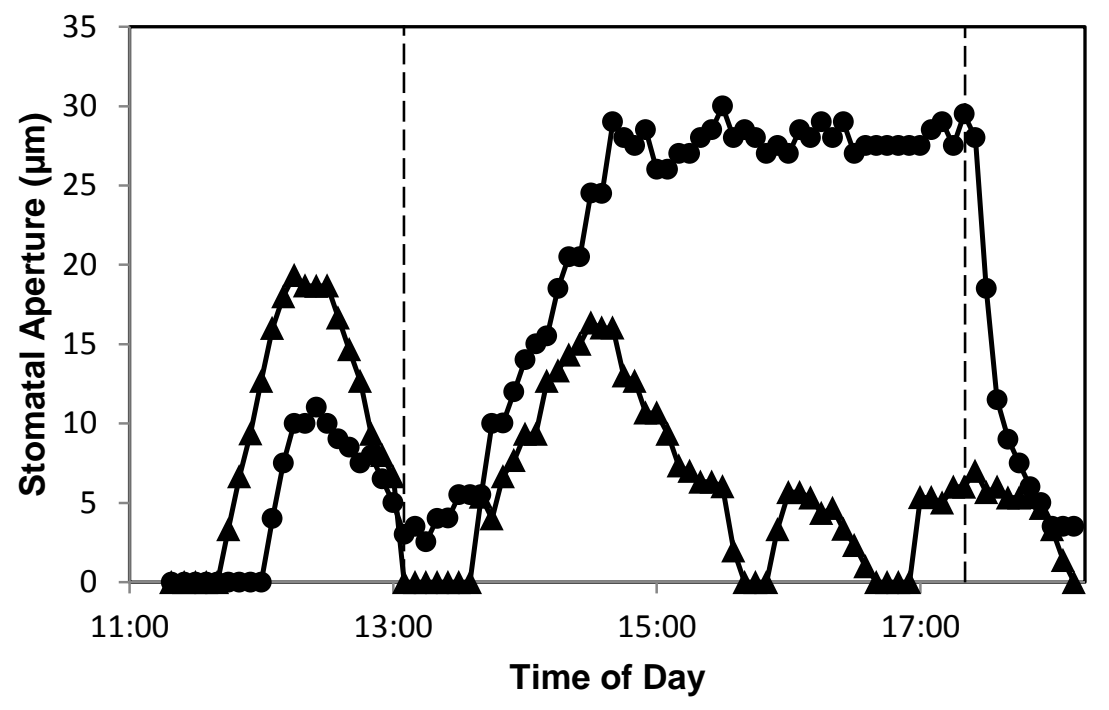

Figure 5. Two individual stomatal apertures over time from a T. pallida leaf subjected to $50 \mu \mathrm{mol} \mathrm{m} \mathrm{s}^{-1}$ of red light over the entire abaxial surface. At 13:16, blue light at 50 $\mu \mathrm{mol} \mathrm{m} \mathrm{m}^{-2} \mathrm{~s}^{-1}$ was applied to one stoma $(\bullet)$ through a fiber optic. The blue light was turned off at 17:22. Aperture for a stoma $1300 \mu \mathrm{m}$ away from the fiber optic was also measured $(\mathbf{\Delta})$. 


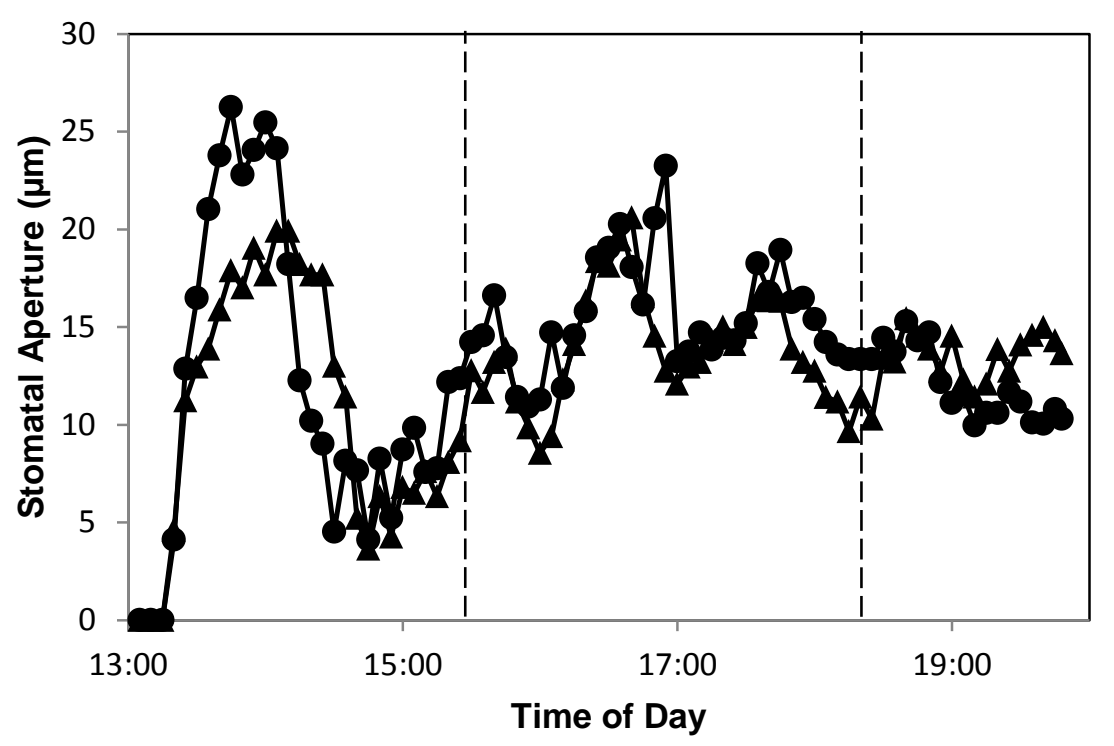

Figure 6. Two individual stomatal apertures over time from a T. pallida leaf subjected to $50 \mu \mathrm{mol} \mathrm{m} \mathrm{s}^{-1}$ of red light over the entire abaxial surface. At 15:27, red light at $50 \mu \mathrm{mol}$ $\mathrm{m}^{-2} \mathrm{~s}^{-1}$ was applied to one stoma $(\bullet)$ through a fiber optic. The fiber optic's red light source was turned off at 18:20. Aperture for a stoma $750 \mu \mathrm{m}$ away from the fiber optic was also measured ( $\mathbf{\Delta})$. 


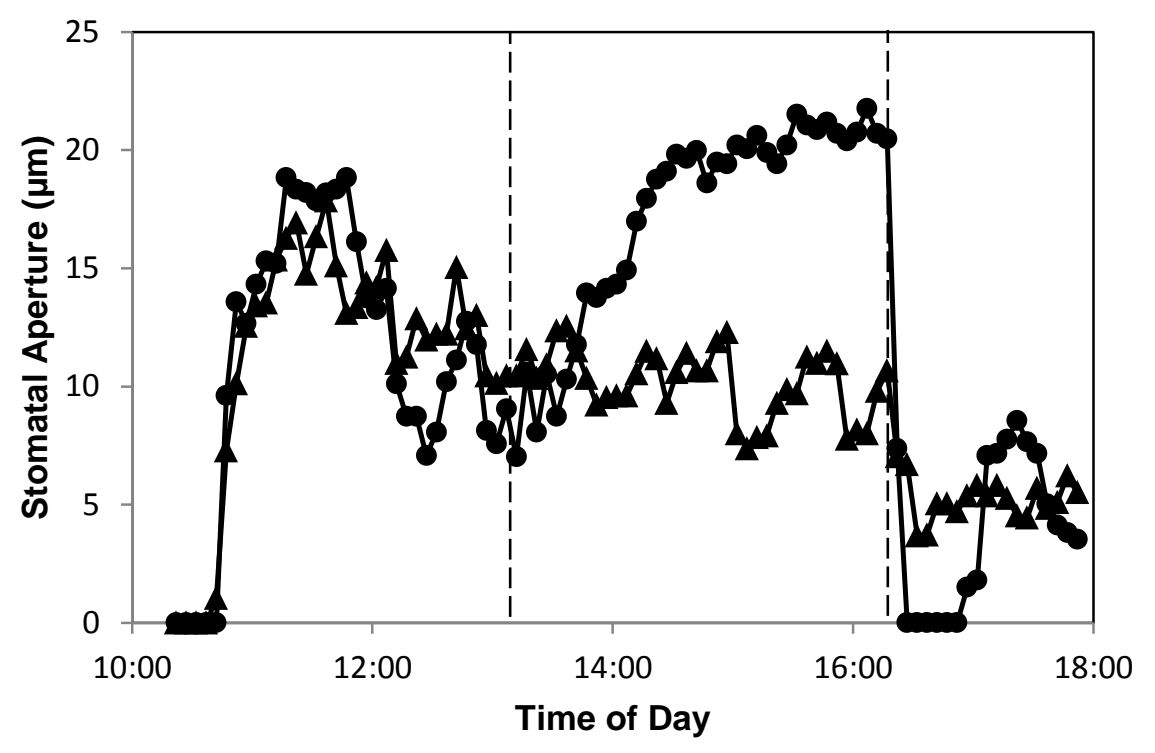

Figure 7. Two individual stomatal apertures over time from a T. pallida leaf subjected to $50 \mu \mathrm{mol} \mathrm{m} \mathrm{s}^{-1}$ of red light over the entire abaxial surface. A fiber optic was used to supply blue light (50 um) to a region of the epidermis lacking guard cells starting at 13:08. This blue light was subsequently removed at 16:14. Stomatal apertures were measured for a pair of guard cells $650 \mu \mathrm{m}$ away from the blue light $(\bullet)$ and a pair of guard cells $1500 \mu \mathrm{m}$ away from the blue light $(\mathbf{\Lambda})$. 